\title{
La interculturalidad, la ruptura, la conciencia de mundo y lo abismal. Aportes para una epistemología antropofágica desde el sur*
}

\author{
Federica Scherbosky ${ }^{* *}$
}

\begin{abstract}
Resumen
En este trabajo se desarrollan diferentes aportes que cuestionan las nociones epistemológicas clásicas por dividir los campos de saber en aquellos que son susceptibles de ser estudiados y aprendidos y aquellos que no lo son, pues escapan al saber considerado como tal por la academia o por cierta hegemonía del conocimiento. Se proponen entonces algunas perspectivas que cuestionan esta dicotomía y la noción de totalidad como base de la misma, como por ejemplo, la filosofía intercultural, desde la obra de Raúl Fornet-Betancourt; la ruptura como ínsita al concepto, analizada por Arturo Roig; la conciencia de mundo producto de la simultaneidad propuesta por Alexander Von Humboldt y por último la noción de lo abismal desarrollada por Boaventura de Sousa Santos. Se considera en un principio que estas perspectivas aportan a lo que podríamos pensar como una "epistemología del sur". Sin embargo se pretende aquí avanzar desde esa noción a lo que se postula como una "epistemología antropofágica". Para ello se desarrollan algunas nociones fundamentales del movimiento de vanguardia brasilera de los años veinte, a fin de abrir camino en la consolidación de esta perspectiva epistemológica nueva.

Palabras clave: Movimiento antropofágico, epistemología del sur, filosofía intercultural, conciencia de mundo, filosofía latinoamerincana.
\end{abstract}

\footnotetext{
* Recibido: marzo 2017. Aceptado: junio 2017

** Universidad Nacional de Cuyo / Consejo Nacional de Investigaciones Científicas y Técnicas. 


\title{
Intercultural philosophy, rupture, consciousness of world and the abysmal. Contribution to an Anthropophagic Epistemology from the South
}

\begin{abstract}
This work develops different contributions that challenge the epistemological classic notions to dividing fields of knowing in those who are susceptible of being studied and learnt and those who are not, beyond the knowledge considered as such by the Academy or by certain hegemony of knowledge. We propose some perspectives that question this dichotomy and the notion of totality as its basis, as for example, intercultural philosophy, from Raúl Fornet-Betancourt; the rupture like a function of the concept itself, analyzed by Arturo Roig; the consciousness of world product of the simultaneity proposed by Alexander Von Humboldt and finally the notion of the abysmal developed by Boaventura de Sousa Santos. These perspectives contribute to think an "epistemology of the South". However, we expect here to advance from that notion to other, that is postulated as an "anthropophagic epistemology". So some basic knowledge of the Brazilian avant-garde movement of the 1920s are developed in order to pave the way in the consolidation of this new epistemological perspective.
\end{abstract}

Keywords: Antropophagic Movement, epistemology of the South, intercultural philosophy, consciousness of world, Latin Amerincan philosophy.

Desde mediados del siglo XX, sucesos como el cambio en el ordenamiento geopolítico del mundo, la descolonización y la aparición de nuevos actores sociales afectaron directamente sobre la disciplinarización de las Ciencias Sociales y Humanidades, situación que dio lugar al cuestionamiento del tipo de conocimiento que éstas producían. Surgieron entonces dentro de los estudios no-eurocéntricos temáticas centradas en la importancia de lo local, la tensión entre lo local y lo universal, las condiciones de producción del conocimiento, la problemática de la recepción, entre otras, junto con nuevos espacios, más allá de las disciplinas, que han contribuido a desestabilizar la división tradicional del conocimiento como son los estudios latinoamericanos y los estudios poscoloniales. Florez Malagón afirma que los nuevos campos, 
que pretenden superar la tradición del conocimiento occidental, no constituyen disciplinas, sino espacios transdisciplinares, pues reconocen las limitaciones que imponen las fronteras y los supuestos rígidos de la división del trabajo intelectual para el abordaje de los fenómenos sociales. Además afirma que estos campos no presentan sus propios principios, teorías o métodos, sino que se apropian de las teorías y metodologías de distintas ciencias sociales y las adaptan a sus propósitos. (Florez Malagón, 2002:7). Cuestión que podría pensarse como una operación claramente antropofágica, al deglutir las diferentes teorías y métodos exclusivos de algunas disciplinas para producir teorías y métodos propios que atiendan de otro modo, más certero quizás, a una realidad particular y compleja.

Estos espacios, en principio transdisciplinares, se alejan de la tradición universalista del conocimiento occidental. Reconocen que todo conocimiento está situado temporal y espacialmente, sin suponer la neutralidad del mismo. Es decir, todo conocimiento surge en un contexto histórico determinado y ante las preguntas particulares de un investigador que también está situado históricamente, no es imparcial ni apolítico. En palabras de Florez Malagón "Los nuevos espacios de conocimiento poseen y reconocen una dimensión política intrínseca y enfatizan el valor del trabajo intelectual comprometido políticamente". (Florez Malagón, 2002:8).

Sin embargo, no sólo se pretende constituir estos nuevos campos de conocimiento, sino también construir y visibilizar nuevos espacios epistemológicos para el análisis de la realidad social, que se aparten de la visión exclusivamente occidental del mundo, junto con el lenguaje y los conceptos por ella utilizados. Se plantea la necesidad de utilizar categorías propias para analizar los fenómenos sociales y las diferentes problemáticas de sujetos inmersos en realidades no hegemónicas. Florez Malagón afirma al respecto que las nuevas formas de conocimiento implican la necesaria renovación de las estructuras institucionales a través de las cuales ellas se imparten. El desafío es buscar otras formas de producir conocimiento. La academia latinoamericana debe pensarse desde su inserción en el mundo global, teniendo en cuenta lo que ello implica en relación a la conformación de la identidad intelectual; por lo que tendría que enfocarse en modificar las rígidas demarcaciones disciplinares que no parecen hoy adecuadas para abordar los fenómenos sociales. Se trata de reflexionar sobre los problemas particulares que abruman a la sociedad para consolidar nuevos saberes que como herramientas emancipadoras constituyan la base de un conocimiento latinoamericano, ya no como reproducción metropolitana, sino como producción autónoma e independiente (Florez Malagón, 2002:10-12). En esta línea de análisis es que se consi- 
dera pertinente pensar estos aportes epistemológicos desde una perspectiva antropofágica, a modo de operación de mixtura, como la deglución necesaria de los conceptos, herramientas y métodos que sean pasibles de aportar en la consolidación de una epistemología propia, desde el sur. Desde una perspectiva antropofágica se piensa que esta identidad intelectual latinoamericana que se propone construir no es una mera adaptación o copia lavada de lo que sucede en los centros hegemónicos de producción del conocimiento. Hay una deglución, una apropiación de lo que se considera provechoso y una eliminación del resto. Hay un distanciamiento de las nociones de "mala copia" o de "error" porque se trata justamente de una mixtura singular que da cuenta de una realidad diferente de la del centro, considerado como ese lugar hegemónico de producción de conocimiento, que no es adaptable sin más a estas latitudes ${ }^{1}$. La noción de antropofagia proviene del Movimiento Antropofágico brasilero, que surge en San Pablo en la década del 20. Surge como un movimiento de vanguardia, en un cruce de estética, política, ética, que se enfrentan al problema de constituir una cultura nacional, una identidad propia, una ciudadanía acorde a un Estado naciente, siempre acechados por la importación europea. Retoman como metáfora la práctica caníbal de la etnia de los tupinambá, que se devoraban al enemigo más valeroso para incorporar lo mejor de la etnia contrincante. A partir de diferentes análisis sobre el tema es que se plantea la antropofagia como una alternativa ética, política, estética y por qué no epistemológica a las nociones de mestizaje e hibridación que subsumen la alteridad y en el mejor de los casos la folklorizan. Se plantea como una alternativa que centra la conflictividad como ínsita a la constitución misma del sujeto y de la cultura, pues se da fruto de una polémica y se la revaloriza. Desde esta perspectiva es que se considera que la propuesta de una epistemología en clave antropofágica incorpora las reivindicaciones de una epistemología del sur, pero a su vez la potencia poner como eje el conflicto con la alteridad, sea esta un sujeto singular, una cultura o una teoría que se me presenta como ajena².

\footnotetext{
${ }^{1}$ Se utiliza "centro" como noción simbólica estandarizada. Sin embargo se propone una crítica a esta noción, ya que se considera que obstaculiza la posibilidad de pensar una dinámica propia de estas latitudes y su vinculación con Europa y/o Estados Unidos. Para ampliar este desarrollo cfr. Scherbosky, Federica. Deglutiendo centros y periferias: la alternativa antropofágica. En: Alpha. Revista de Artes, Letras y Filosofía. (en prensa 2017).

2 Para ampliar la noción de antropofagia cfr: De Andrade, O. (2008), Escritos Antropófagos, Buenos Aires: Ediciones Corregidor. De Campos, H. (2000), De la razón antropofágica y otros ensayos, México: Siglo XXI. Rolnik, S. “Antropofagia zombie”, en Brumaria 7 arte, máquinas, trabajo inmateria, disponible en: http://www.brumaria.net/textos/Brumaria7/14suelyrolnik.htm (Última consulta 20 de julio de 2013). Scherbosky, Federica (2011) "La subjetividad antropofágica: aportes para una concepción devorativa de la vida”. En: Estudios de Filosofia Práctica e Historia de las Ideas. N 12. INCIHUSA. CONICET. Mendo-
} 
En consonancia con lo antes señalado es que este trabajo pretende hacer un aporte a la construcción de una epistemología que contemple la perspectiva del sur a partir de una mirada intercultural, de ruptura, que tenga en cuenta la conciencia de mundo producto de la simultaneidad y lo abismal. Y a partir de estos aportes desde una perspectiva del sur se plantea la posibilidad de una epistemología antropofágica. Pero antes de avanzar es necesario detenerse, aunque sea brevemente, en aquello que se piensa en clave de una "epistemología del sur" para sumar a partir de allí esta nueva perspectiva antropofágica.

Epistemología del sur responde a un concepto acuñado por Boaventura de Sousa Santos, en un libro homónimo publicado en México en 2009. En este comienza asumiendo un problema en la ciencia, y analiza sus crisis y las posibles alternativas epistemológicas que conlleva -sin duda alguna para él- un posicionamiento político. La epistemología del sur implica pensar la producción de saberes en el entramado de relaciones de poder marcadas por la colonización y el capitalismo. Cuestiones que se pueden pensar como temáticas comunes a los autores propuestos en este trabajo. Boaventura señala, en consonancia con lo anteriormente mencionado, una crisis en el saber occidental, que implica poner en cuestión la imagen del paradigma científico dominante, marcado por la cuantificación y las dicotomías. Esto repercute de manera directa en cómo se ha organizado la trasmisión de este saber, es decir, en el saber universitario. Instancia que no escapa a las mencionadas dicotomías que se plasman en saberes celosamente disciplinares. Un diagnóstico muy similar es el realizado por Florez Malagón en lo que respecta a los límites disciplinares de las ciencias sociales, y también por Fornet-Betancourt (como se analiza más adelante) en relación con la academia y su normalización de saber, proponiendo como alternativa cruces interdisciplinares en busca de saberes interculturales genuinos.

La imposición del paradigma científico dominante implica, en palabras de Boaventura, un "epistemicidio", por destruir formas diversas del conocimiento, que no entran en la totalidad cerrada dispuesta por el pensamiento hegemónico, guiado por el lema del progreso y de una linealidad del tiempo. La epistemología del sur implica eliminar la dicotomía, por ejemplo entre ciencias sociales y naturales y abrir el conocimiento en todas sus posibilidades. Se trata de allanar el camino hacia "un conocimiento prudente para una vida decente" (de Sousa Santos, 2009: 40). Al proponer el concepto de "epis- 
temicidio" analiza la eliminación o la no realización de diversos conocimientos bajo su noción de "sociología de las ausencias", frente a la que propone una "epistemología de las ausencias" que abra la posibilidad de visibilidad y realización a todos esos saberes negados, sojuzgados o simplemente no realizados. Se trata de expandir el concepto de realidad más allá de lo fáctico, hacia lo imaginado o lo emergente. Esta epistemología propone también la modificación de las nociones de saber e ignorancia, ya que estos no son absolutos, pues se dan siempre en relación con un objeto. La idea no es equiparar todos los saberes al conocimiento científico, sino ser flexibles en los modos de validación de estos. En este sentido se considera que la reflexión desde y para una epistemología del sur en el quehacer académico es fundamental ya que este siempre está vinculado a las tramas de poder en las que los saberes están insertos. Este entramado de saberes atravesados por la colonialidad y el capitalismo acecha una supuesta totalidad que nunca es tal, pero que se impone como frontera marcando el adentro y afuera de cada disciplina o conocimiento susceptible de ser o no sabido, en consecuencia, de sus modos de validación.

En función de la ruptura de esta supuesta totalidad, como así también de la crítica a los límites disciplinares y de la revalorización del concepto como ejercicio de ruptura, como así también de la conciencia de mundo a partir de la cual se construye conocimiento, es que se analizan cuatro aportes que se consideran centrales, pues ayudan a pensar desde el cruce disciplinar: la propuesta de Raúl Fornet-Betancourt (1946), la de Alexander von Humboldt (1769-1859) la de Arturo Roig (1922-2012) y la Boaventura de Sousa Santos (1940), quienes hacen camino en este ámbito.

Podría resultar extraño, o quizá anacrónico, la referencia a von Humboldt junto a autores contemporáneos. No obstante, se considera igualmente pertinente por dos motivos. En primer término, porque se lo analiza desde las lecturas que realizan autores contemporáneos, particularmente O. Kozlarek, O. Ette y J. Misch. En segundo lugar, estas lecturas contemporáneas de von Humboldt dan cuenta de su actualidad y de la pertinencia de sus aportes para analizar las tramas actuales del conocimiento. Además en consonancia con los autores trabajados en esta propuesta epistemológica antropofágica desde el sur se sostiene que existen diversas voces en cada momento histórico, pero que la mayor parte de las veces no se visibilizan pues se impone una de ellas, que se erige como la posición hegemónica. Se torna interesante entonces destacar una propuesta como la de von Humboldt ya que se posiciona como una de esas voces alternativas a la dominante y se da como un buen ejemplo de una práctica intercultural, pues se atiende a la multiplicidad de voces en un 
contexto determinado y así la complejidad del universo discursivo da cuenta de las tensiones propias del mismo. Cabe señalar también que la propuesta de von Humboldt es contemporánea a otras -como la de Hegel por ejemplo- cuyos planteos son radicalmente distintos. Esto patentiza los diversos modos posibles para comprender una situación determinada, en este caso la Modernidad. Por esto el interés en volver a su obra, pues posibilita complejizar un fenómeno diverso como el de la Modernidad y a partir de estas nuevas perspectivas sobre el mismo se abren nuevas posibilidades para pensar los tiempos actuales.

Los autores propuestos intentan pensar modos de apertura a la alteridad, buscando abrir espacios donde quepa lo desconocido. Se trata de hacer un lugar a aquello que está por fuera del canon, que existe, ciertamente, pero invisibilizado por la tradición dominante. Se hace necesario entonces un corrimiento epistemológico que proponga nuevos modos de pensar la realidad, bajo nuevas categorías y con nuevas herramientas.

\section{Raúl Fornet-Betancourt: una propuesta interdisciplinar e intercultural}

Raúl Fornet-Betancourt inicia sus reflexiones sobre la Transformación Intercultural de la Filosofía (2001) preguntándose por la norma que rige el quehacer de la filosofía. Considera que la historia de la institucionalización y de la profesionalización de la filosofía marca el desarrollo de la misma e incluso la propia concepción de la filosofía, pues se la percibe como una actividad profesional cultivada por especialistas en determinados marcos institucionales -como instituciones universitarias o académicas en general-. Esta imagen ha sido moldeada por la historia de la institucionalización académica y por los sujetos que se ocupan de ella, ya que la consideran desde su propia actividad docente, o como investigadores, obviamente dentro de determinadas instituciones, con reglas específicas y un canon que debe seguirse. El concepto de "normalidad filosófica" propuesto por Francisco Romero sintetiza esta práctica. Según Fornet-Betancourt esta "normalidad" se torna "evidente". Con la historización de tal "evidencia" de una determinada normalidad y de un determinado canon marcado por la institucionalización, Fornet-Betancourt señala que esta reducción de la filosofía a la práctica académica y a un canon determinado de autores y obras produce una "deformación profesional" que se manifiesta en dos dimensiones: por un lado en la concepción y el quehacer del "oficio" de los filósofos y por otro en la concepción misma de la filoso- 
fía, siempre ligada a esta forma canónica de filosofía "normalizada"3. Una característica fundamental de esta concepción academicista de la filosofía es el culto a la tradición escrita y la transformación de la filosofía en arte interpretativo. Esta tradición implica a su vez una pretensión de universalidad que supone expandir lo propio, a partir del canon marcado por la academia, sin la posibilidad de abrirse a otras tradiciones. Este modelo cuya imagen se ha tornado "evidente" oculta que la filosofía se desarrolla también como un saber contextual y allí radica el núcleo de la crítica de Raúl Fornet-Betancourt. Retoma a Hegel para sostener que incluso él -clásico exponente criticado por racionalista y eurocéntrico- postula como tarea de la filosofía el pensar el mundo histórico real y no construir un mundo aparte. A partir de la propuesta de aprehender su tiempo reflexivamente que retoma de Hegel -en sus Principios de Filosofía del Derecho (1821)- considera que “(...) es consecuente entonces admitir que hay otro desarrollo de la filosofía; que la filosofía se ha hecho en otras historias que no son ésas de su institucionalización y que presenta una pluralidad de formas en la que se refleja precisamente su calidad de saber o reflexión contextual" (Fornet-Betancourt, 2001:12). Es por ello que la propuesta intercultural se sostiene en una necesidad concreta de apertura a esas otras filosofías contextuales tradicionalmente acalladas. Theodor Adorno en su crítica a la dialéctica hegeliana propone también pensar por fuera del concepto de identidad, que subsume a la alteridad en función de "lo mismo". Se distancia de las totalidades cerradas y aboga por la posibilidad de mantener el sistema abierto, en su negatividad, ya que allí puede surgir la diferencia. Esta contextualidad que sostiene Fornet-Betancourt como fuente de pluralidad trata de la singularidad que presenta cada filosofía contextual, por haber surgido en una coyuntura determinada. Ninguna otra tradición podría reemplazarla o tomar la palabra por ella, pues lleva en sí misma la razón de su propia necesidad.

Aquí es donde se hace necesaria otra epistemología mediante la cual puedan pensarse aquellas otras tradiciones que no encontraron voz en el espíritu dominante. Esta propuesta filosófica se enlaza entonces con una problematización epistemológica y se presenta como una protesta enérgica contra la historiografía oficial de la filosofía dominante, pero sin buscar ser parte de ella. Por lo que la transformación intercultural que propone no es oposición

\footnotetext{
${ }^{3}$ Para ampliar el concepto de "normalidad filosófica", cfr. Carlos Ossandón, (1979) "El concepto de 'normalidad filosófica' en Francisco Romero", en Revista de Filosofía Latinoamericana 7/8 pp.115-130. También puede ayudar el texto de Leopoldo Zea, "Romero y la normalidad filosófica latinoamericana", en Francisco Romero. Maestro de la filosofía latinoamericana, Sociedad Interamericana de Filosofía, Caracas 1983, pp169.181.
} 
ni queja resentida para que las tradiciones relegadas sean reconocidas por el canon tradicional. No pretende reconocimiento por parte de la memoria hegemónica, sino que busca “( ...) reescribir el mapa de la filosofía desde esos lugares-que-dan-verdad y sus voces propias, portadoras de memorias alternativas hasta ahora periféricas" (Fornet-Betancourt, 2001:16). Fornet-Betancourt propone impulsar, en consonancia con la propuesta de Boaventura de Sousa Santos, un programa de universalización desde el Sur, cuya base es el diálogo con otras tradiciones. A través de la apertura a otras voces logra liberar la universalidad de toda carga imperial, como aquella que se impone desde una tradición dominante. Propone un saber intercultural del mundo cuyo objetivo sea una universalización a partir del diálogo entre tradiciones contextuales.

Además, asumir el diálogo intercultural y sus necesarias transformaciones epistemológicas implica asumir también que la filosofía siempre pudo y puede ser de otra forma. Se abren otras posibilidades futuras y se vuelven a pensar históricamente las supuestas verdades dadas como apodícticas. Debe considerarse si los conceptos de que se dispone posibilitan ciertamente desarrollar esta propuesta o si en realidad no están estancando el proceso por intentar encorsetar en ellos transformaciones que los exceden. Sucede esto con la controvertida categoría de "totalidad" que fija y cierra, por lo cual Fornet-Betancourt prefiere hablar de una "totalización dialéctica", en la que la verdad se da como proceso, puesto que ninguna cultura es el lugar definitivo de la verdad. Este concepto de "totalización dialéctica" proviene de su estudio sobre Sartre, pero el filósofo cubano lo transforma en un ejercicio de reflexión subjetiva entre lo propio del sujeto y su cultura. En el "universal singular" que es el sujeto, siempre hay un resto no culturizado, que le permite no sólo un momento reflexivo crítico de la propia cultura, sino sobre todo el diálogo con el otro. Esta reflexión subjetiva convierte los límites en fronteras y así habilita la comunicación intercultural, pues como el sujeto es siempre una exterioridad puede poner en cuestión la propia identidad cultural de origen. El diálogo intercultural ofrece distintas posibilidades para poner en marcha el proceso discursivo hacia la verdad. Sostiene así el autor: "Como proceso aparece la 'verdad' sólo a condición de que cada uno acepte poner en juego su verdad y la someta a la dialéctica de la contrastación que se crea necesariamente por el carácter interdiscursivo del diálogo intercultural" (Fornet-Betancourt, 2001:48). Al mismo tiempo la dialéctica de la contrastación se presenta como un límite al relativismo histórico-cultural que, en el fondo, se sostiene en el aislamiento, pues radica en la ilusión de que cada sujeto o cada cultura puede esgrimir los parámetros o valoraciones que desee, aunque estos anulen las de otro. Para el relativismo cultural cualquier opción tendría 
validez. Sin embargo, pensar la verdad como proceso, someterla a la contrastación propia de la propuesta intercultural, elimina esta posibilidad del relativismo, ya que se logra una objetividad o verdad intersubjetivamente consensuada.

Cabe destacar también que la filosofía intercultural propone un descentramiento de la reflexión filosófica y en virtud de ello toma distancia de cualquier centralidad -no sólo la europea-. Así la interpretación de lo propio y lo ajeno irá sucediéndose como resultado de la interpelación mutua, donde ciertamente se parte de lo propio pero sabiéndolo tránsito y puente para la intercomunicación. La identidad ya no se presenta de manera esencial y estática, sino como un proceso histórico de enriquecimiento continuo a partir de la intercomunicación propuesta. Esto modifica, como ya se mencionó, la noción de universalidad; en efecto, al historizar y contextualizar la identidad, aquélla se da como resultado de la interpelación del otro. De este modo la noción de universalidad se desliga de la figura de la unidad, tal como ha sido comprendida tradicionalmente. Fornet-Betancourt incluso sospecha que hasta ahora no se ha conocido, ni menos aún realizado históricamente la universalidad, puesto que se la hipotecaba con la idea de unidad. Propone en cambio rehacer la idea de universalidad, pero centrada ahora en el fomento a la solidaridad entre todos los "universos" que componen el mundo, ya que esta multiplicidad de voces no está ordenada a priori por una unidad metafísica. Son históricas, contingentes y se articulan desde el trasfondo irreductible de distintos mundos de vida, manifestando así su autonomía intelectual. Esta autonomía implica defender la propia voz, la posibilidad de articular un discurso propio que a la vez limita el peligro de "ser hablado" por otro, como así también de querer representar o erigirse como portavoz de la alteridad. No es posible ponerse en el lugar del otro, sino sólo abrir el espacio para que éste articule su palabra. Ya no es viable pensarlo como objeto de interés u objeto de investigación, "(...) porque el otro no es ya mera materia para pensar por un pensamiento dispuesto precisamente a asimilarlo como lo 'pensado' o 'conocido', sino sujeto de un pensamiento propio en proceso" (Fornet-Betancourt, 2001:37).

Esto impulsa a replantear los presupuestos de la propia teoría del entender como un desafío hermenéutico y la necesidad de historizar este mismo problema a la luz de los procesos actuales, pensando específicamente en los conflictos Norte-Sur. Se trata de analizar los supuestos que se dan con el proceso de la globalización, que implica una imposición de algunos núcleos económicos y conceptuales del Norte -sobre todo Estados Unidos y Europa- sobre el resto de los países del Sur, con la aparente idea de una distribución igualitaria 
del acceso a la información, al poder y a los recursos. Esto se sustenta en una ideología que encubre la desigual repartición del mundo, ya que la globalización se erige como una universalización de políticas neoliberales que acentúa la desigualdad. Propone el filósofo cubano recuperar la tradición del humanismo crítico-ético, que implica una formación de la existencia humana como subjetividad participativa en relación con un ordenamiento comunitario. Por ello la subjetividad se sabe siendo ya en relación siempre con otro. Desde esta perspectiva es que critica los conflictos Norte-Sur generados a partir del proceso de globalización y propone principios para actuar frente a la misma. Hay una modificación de la noción de sujeto, ya que se abandona el sujeto cartesiano -dominador-para asumir un sujeto de la tradición del humanismo crítico-ético, cuestión que implica a la vez una superación del paradigma de la posesión por el paradigma de la justicia. Debe destacarse que la globalización implica además de la universalización de políticas neoliberales, el colonialismo y posterior imperialismo, que pueden quedar encubiertos si no se realiza una crítica a la globalización como discurso ideológico, cuestión en la que Fornet-Betancourt coincide una vez más con el sociólogo portugués. Si bien algunos postulan una posible "glocalización", que acentúa la dialéctica entre lo global y lo local, no obstante lo que se propaga como "universal" o "global" es una cultura occidental capitalista de "primer mundo", sin el necesario reconocimiento del derecho a la autodeterminación por parte de las culturas "locales". En el fondo se trata de nuevas formas de dependencia, más que de un mundo interdependiente. Cuestión que podría modificarse en tanto los sujetos y las comunidades logren su autodeterminación y conozcan su contexto. Como bien señala José Martí a modo de principio: "injértese en nuestras repúblicas el mundo; pero el tronco ha de ser el de nuestras repúblicas" (Martí, 1975:18). Así, aunque la razón filosófica pueda ser una, las filosofías en que se expresa esa razón son plurales. Pero este pluralismo no tiene que ver, como bien afirma Fornet-Betancourt “(...) con el colorido superficial de un culturalismo costumbrista o folklórico sino con los mundos de interpretación donde echan sus raíces y desde los que se articulan como voces contextuales" (Fornet-Betancourt, 2001:310).

\footnotetext{
${ }^{4}$ Es importante señalar en función de los mencionados conflictos Norte-Sur la consecuente propuesta de los "Diálogos Norte-Sur" que han sido llevados a cabo por iniciativa de Fornet-Betancourt desde 1985. Estos encuentros han sido centrales para poner en práctica diálogos interculturales en función de las problemáticas actuales. Estos encuentros han quedado documentados en las diferentes actas que se desarrollaron en cada ocasión, pero para una comprensión de su historia, motivaciones, fortalezas y dificultades, cfr. Fornet-Betancourt, Raúl (2004) “El Programa de Diálogo Norte-Sur. Historia de un proceso y balance provisional” en: Filosofía para la Convivencia. Sevilla. MAD.
} 


\section{Alexander von Humboldt, acerca de la conciencia de mundo y del pensar sincrónico en movimiento}

En lo que respecta a Alexander von Humboldt se analiza su propuesta desde la rehabilitación que hace de él Ottmar Ette, quien, si bien proviene del campo literario, específicamente de las lenguas románicas, se apropia de distintas concepciones de von Humboldt para repensar otra epistemología sustentada en una concepción de conocimiento complejo. En Weltbewußtsein. Alexander von Humboldt und das Projekt einer anderen Moderne [Conciencia de mundo. Alexander von Humboldt y el proyecto de otra modernidad] (2002) sitúa como categoría central la "conciencia de mundo". Esta "conciencia de mundo" pretende hacerse cargo de la multiplicidad de escenarios en los que se representa el mundo, buscando volver visibles las diferentes perspectivas invisibilizadas por el canon, por aquella perspectiva hegemónica que oculta a las demás. A partir de este nuevo entramado conceptual, que pone el acento en la compleja diversidad del mundo, es que se considera posible incorporar a este pensador al banquete, para elaborar una epistemología antropofágica.

El concepto de "conciencia de mundo" surge en respuesta a la imponente expansión geográfica y al sistema mundial de la modernidad. Sin embargo, von Humboldt concibe una modernidad distinta, en la cual, junto con la novedosa expansión, debía constituirse una red global de relaciones humanas. Considera que el saber es un campo de interrelaciones, tanto en referencia a las diferentes disciplinas científicas como a la convivencia de culturas diversas, ya que logra percibir el proceso de la modernidad no sólo desde la sucesión, sino también y fundamentalmente desde la simultaneidad. Ette sostiene que la propuesta de von Humboldt es un "pensar sincrónico en movimiento" y Oliver Kozlarek destaca que el planteo humboldtiano posibilita pensar de otro modo la modernidad, ya que al priorizar el espacio relativiza el tiempo lineal, que conlleva la idea de progreso, y, en consecuencia, de dominación colonial. Este filósofo moderno logra, así, abrirse a otras formas de pensar la modernidad. Comenta Kozlarek: "En vez de ajustar el entendimiento de la modernidad a una epistemología dominada por una lógica temporal, que era tan conveniente para la justificación del orden colonial así como también para las hegemonías geopolíticas poscoloniales, von Humboldt prefiere una epistemología que favorece el espacio" (Kozlarek, 2009: 84).

Kozlarek retoma también a Ernst Cassirer, quien sostiene que una epistemología fundada en el tiempo sólo puede explicar cambios o modificaciones en torno a la sucesión, mientras que si se hace hincapié en la dimensión espacial se abre a la posibilidad de comprender la simultaneidad de aspectos que 
se dan en un mismo momento. Estas operaciones requieren de una sensibilidad capaz de percibir las diferencias que se dan en diversos lugares simultáneamente, favoreciendo así la complejidad y la contingencia.

La radicalidad de su planteo -como bien reza el título del libro que Ette dedica a von Humboldt- abre la posibilidad de pensar el proyecto de otra modernidad, cuyos contornos llegan a ser visibles y explicables desde la perspectiva actual. Como señala el autor, sólo cuando se logra no aislar el pensamiento y la actitud de von Humboldt de los contextos históricos, sociales y biográficos de su época, puede convertirse en nuestro contemporáneo.

El saber que proponía von Humboldt necesitaba de la participación social que era pensada en términos de democratización del saber, ya que por medio de las nuevas redes de comunicación que empezaban a generarse se volvía materialmente posible. Con los nuevos avances tecnológicos que acercaban las distancias y permitían mayor acceso a la información, pensaba el geógrafo, podían generarse mayores y mejores accesos al conocimiento, en función de tales nuevas redes de comunicación. No se trataba solamente de la ampliación del conocimiento sin más y de la aceleración con que esto se producía, sino también de la distribución equitativa del mismo. A partir de su propuesta de "conciencia mundo" era posible no sólo conocer diferentes perspectivas existentes de hecho, sino además hacer accesibles las novedades a todas las culturas del globo. Estas nuevas redes de comunicación abrían la posibilidad de un acceso generalizado al conocimiento. Von Humboldt pensaba conjuntamente regiones, disciplinas y culturas diferentes desde una perspectiva comparada. Las conclusiones debían presentarse de manera provisional, siendo posible someterlas a nuevas comparaciones. Sólo contrastando y comparando el "mundo propio" con "otros mundos" era pensable tener una "conciencia de mundo" que permitiera hablar del todo sin ignorar lo singular. No obstante, conserva la idea de totalidad pero como idea regulativa y construida a partir del encuentro concreto con el otro.

Aunque el autor se sitúa desde una perspectiva europea, ésta no le impide abrir su mirada hacia otros horizontes. No sólo le resulta imposible desentenderse de ellos, sino que se le hace imperioso conocerlos para conformar esta totalidad que es parte fundamental del "sistema mundo" de la modernidad. Por esto su crítica a Hegel está dirigida a la falta de fundamento empírico de las afirmaciones absolutas del filósofo, que revelan sintomáticamente la falta de una experiencia del mundo que von Humboldt considera ineludible. La crítica se dirige también a la sistematicidad y a la teleología inmanente de los sistemas filosóficos y científicos hegelianos. El proyecto de von Humboldt, en cambio, se presenta como un proceso de conocimiento abierto al mundo en 
movimiento permanente, fruto de la comunicación global y del intercambio mutuo. No hay posibilidad de clausura como en el pensamiento hegeliano, sino, por el contrario, se postula una apertura de espacio permanente para que la diversidad se manifieste y entre en diálogo. Se contrapone el cierre de cualquier sistema -a modo hegeliano- a la apertura, comparación y diálogo entre diferentes visiones de mundo. La conciencia del mundo siempre es provisoria; la totalidad es una idea regulativa que se articula en función de la dinámica dialógica con la perspectiva del otro. Este movimiento que plantea von Humboldt posibilita la modificación del pensamiento y de los parámetros con los cuales se va gestando la totalidad. Como la totalización dialéctica que retoma Raúl Fornet-Betancourt, se trata de pensar la totalidad pero sin que ésta subsuma lo singular. Cada contexto, cada perspectiva, cada visión de mundo forman parte de esta totalidad que se va conformando en base al intercambio; se parte de la singularidad, pero sabiéndola también tránsito hacia una totalidad o conciencia de mundo renovada. No se trata sólo de conocer otras visiones de mundo, sino de dejarse afectar por ellas. Las nuevas perspectivas producen el cuestionamiento de la propia, que se sabe siempre provisional. En la misma dirección se encuentran los aportes de un estudioso del pensamiento de von Humboldt, quien sostiene que:

[...] la ciencia que Humboldt propone no se basa simplemente en el acoplar conocimientos y experiencias en un sistema de pensamiento prefabricado, sino en la relación que se establece entre el análisis y la síntesis, entre la recogida de datos y la generalización, entre la observación particular y la conclusión siempre provisional que se obtiene y que es el resultado de un modo de proceder comparativo. (Misch, 2004: 572)

Es posible concluir que Von Humboldt realiza un aporte sustancial a esta propuesta epistemológica del sur, pues aunque situándose en el norte, construye herramientas antihegemónicas y de revalorización de la diversidad que usualmente es negada por este mismo proceso de modernidad colonizadora a la que le hace frente. Interesa destacar también que esta noción de "conciencia de mundo", pues se considera podría ser resultado de una operación antropofágica, al darse como fruto de la incorporación de los diversos mundos con los que entró en contacto. La conciencia de mundo implica poder mezclar, incorporar, hasta el punto de "hacer carne" las diferentes visiones de mundo que la alteridad presenta. Es también en este sentido que interesa sumar su aporte. 


\section{Arturo Roig o el concepto en su función de ruptura}

Otro contexto que plantea una ampliación epistemológica a partir del cuestionamiento del sujeto y el ámbito en el que se produce filosofía es Arturo Roig. Éste se interroga por el sujeto del filosofar y, en función de éste, por la concepción misma de la filosofía. Habilita entonces Roig la pregunta acerca de otro modo de hacer filosofía, en función de otros sujetos y de otras fuentes del filosofar. Para ello se abre a una nueva conciencia de mundo, pues considera la existencia de sujetos y de fuentes ajenas a la filosofía académicamente comprendida. Se cuestiona acerca de una versión única de filosofía, pues considera que dependiendo del sujeto que filosofe y de la metodología con la cual se realice dicha actividad, será el resultado que se obtenga. Esto implica la posibilidad de otras concepciones, que amplíen e incluso cuestionen la establecida. Se trata de una propuesta también emancipadora, que piensa la apertura a otras voces, a otros contextos, que no solo visibilicen a aquellos sujetos ignorados o negados, sino que, además, complejicen las concepciones existentes. Con esta finalidad Roig apela a la Historia de las Ideas y propone en relación con ésta la noción de "universo discursivo". El análisis de los textos debe hacerse en permanente vinculación con la vida social de cada época, siempre relacionada con otras esferas de la realidad social, ya que la reducción y el aislamiento de las diferentes esferas del todo social reduce la posibilidad de tener una conciencia de mundo que dé cuenta de la complejidad ínsita del mismo. En este sentido, Roig propone la apertura a los diferentes ámbitos que conforman el pensamiento y acentúa la dimensión social, económica, política, biográfica que marcan de manera radical el pensamiento, ya que éste presenta como central su función para la vida.

La ampliación de dimensiones que propone el pensador mendocino, como parte del universo que integra el discurso filosófico, posibilita igualmente reflexionar sobre la vida social de cada época con la que la filosofía no debe perder contacto. La ampliación metodológica atiende a un sistema de conexiones en el que la filosofía es tan solo un momento de este sistema que se sostiene en una estructura histórica, ya que, como bien decía Hegel, la filosofía es su época aprehendida en conceptos. Sin embargo, Roig considera que la mencionada ampliación sólo podrá hacerse efectiva si se realiza una crítica del concepto. Afirma Roig que Hegel postula el concepto como la posibilidad de que el pensar se encuentre consigo mismo. Implica así el concepto una función de integración, en el que forma y contenido cierran en una totalidad que posibilita la identificación de ser y pensar. Esto se postula como la "filosofía de la conciencia", del "sujeto", o del "concepto". Sin embargo, el filósofo mendocino considera que la "filosofía de la denuncia" ha abierto 
un nuevo horizonte que atiende a la ruptura propia que se da al interior del concepto mismo, por ello postula en contraposición la "filosofía del objeto" o de la "representación".

La filosofía para Hegel es el saber pensante de una época que surge cuando ésta ha madurado y en ese sentido se da como "reformulación" de una época ya cerrada. La filosofía es siempre clausura, pues solo reformula una totalidad que ya ha alcanzado su culminación. En contraposición al cierre, Roig, junto con la filosofía de la sospecha, destaca lo sensible y la existencia misma, o sea la representación o el filosofema. En éste no hay integración de forma y contenido sino quiebre, ruptura, dispersión y en ese sentido apertura. La filosofía ya no es sólo clausura en tanto cierre epocal, sino que puede abrirse a una dialéctica no necesariamente asuntiva, ya que el propio concepto contiene la posibilidad de integración como así también de ruptura. Si bien se ha priorizado la integración y se ha colocado a la ruptura fuera del concepto, en aquello que atiende a lo sensible, como el filosofema, ambas funciones son constitutivas del concepto mismo (Roig, 1973:222). Distingue Roig estas funciones al afirmar que:

Si nos colocamos ahora en el proceso mismo de constitución del concepto veremos que hay un movimiento dialéctico que va de un primer momento de ruptura a un segundo momento de integración. ... es un movimiento dialéctico en el que el concepto integra en sí mismo lo que se le aparecía como negativo o enfrentado y al negarlo, lo asume. En otras palabras, la función de integración del concepto no es siempre ejercida de un mismo modo, en cuanto que lo dialéctico puede significar ya una clausura, ya una apertura del proceso de integración mismo. (Roig, 1973:222)

Los filosofemas no pueden entrar en la historia de la filosofía, según Hegel, pues sería una ampliación indebida. Roig, de manera opuesta, pretende lograr tal ampliación con su propuesta metodológica donde muestra que integración y ruptura son, ambas, funciones internas del concepto. La representación o filosofema es parte del concepto mismo, cuestión trabajada intensamente por la filosofía de la sospecha. Marx, Nietzsche y Freud muestran cómo en el concepto mismo hay dobleces y cómo, en tal sentido, no hay claridad ni perfecta unidad entre forma y contenido; en la alienación que produce la ideología capitalista, para el primero, en los valores cristianos, para Nietzsche y en el inconsciente, para Freud. Se profundiza entonces la noción de ruptura que no había sido tenida en cuenta por las "filosofías del concepto". El filosofema lleva entonces consigo la función de ruptura que se postula en consonancia con lo sensible. 
Se produce un distanciamiento de la razón y del concepto como lo puramente integrador, pues con anterioridad a la razón está el sujeto oprimido que no forma parte de la misma ya que se lo sitúa de hecho como lo sin-razón. Para el opresor, la razón ordena y jerarquiza, lo que desordena y desjerarquiza al oprimido. En este sentido la temática de la alteridad es central, ya que no se trata de una cuestión de mero academicismo, de una ampliación de sujetos y fuentes por una necesidad filosófica únicamente conceptual. Es en la praxis misma donde estos sujetos no se sienten reconocidos bajo los parámetros o la razón usualmente establecida. Roig sostiene que la alteridad se establece de modo diferente en las filosofías del concepto y en las que priorizan la ruptura, pues en las primeras la alteridad se constituye de modo teórico, como inmanente a la razón, mientras que en las filosofías que reivindican la ruptura se parte de una secreta o subconsciente ansia de la alteridad, como aquella que posibilita la ruptura de la razón ordenadora y justificadora de la integración que realiza el concepto. Para Roig, en un sistema de opresión la alteridad se presenta como el agente de cambio y la apertura a lo nuevo. Sostiene entonces que: "Todo oprimido se siente en cuanto tal, por naturaleza, fuera del sistema y parte del presupuesto de que él es lo extraño, lo nuevo, lo que debe quebrar el sistema, o aceptarlo en el peor de los casos para sobrevivir, no para vivir" (Roig, 1973:230).

La filosofía no puede desligarse entonces de las ideologías y de los discursos políticos que le son contemporáneos, ya que pertenece a una totalidad estructural de conexiones de una determinada época histórica. Hay que despojar a la filosofía de su academicismo pretendidamente apolítico, que genera una concepción de filosofía que evade el conflicto como la ambigüedad propia de la realidad y que se ve reflejada en esta noción del concepto que no contempla la ruptura. En tanto se postule la filosofía como una actividad meramente académica, se despojará a la misma y a los sujetos que la ejercen del contacto con la vida cotidiana y con el sistema de conexiones en el cual está siempre ya inserta.

Según Roig la filosofía como función para la vida depende en su progreso de los horizontes de comprensión y de la posibilidad de apertura hacia esos horizontes que no responden sólo a problemas teóricos. La filosofía en cuanto intento de racionalizar los procesos vividos, de encontrar un sentido, necesita de herramientas metodológicas que le permitan acceder a esos horizontes. La propuesta de Arturo Roig consiste en repensar las herramientas utilizadas hasta el momento, criticarlas y si es necesario ampliarlas o darles un nuevo sentido y un nuevo uso a las ya existentes. Se trata entonces de una constante revisión de las categorías con las que se pretende hacer la filosofía 
latinoamericana, ya que esta tarea reviste una complejidad mayor a la de la filosofía como mero "modelo académico". En la búsqueda de repensar las herramientas metodológicas con las cuales hacer filosofía es que apela a la Historia de las Ideas y se abre a otros campos colindantes con el saber filosófico, rechazados o ignorados por la filosofía y la historiografía oficiales. La aproximación a la Historia de las Ideas permite problematizar las teorías y conceptualizaciones desde las cuales se constituyen identidades, pueblos, historias. Se propicia una filosofía latinoamericana que dé cuenta del contexto en el cual está inmersa, siempre a la luz de una consideración social de las ideas, ya que la unión de filosofía y vida implica poner como centro la vida del pueblo, enfatizando con ello también los problema de clases, étnicos, de género, etc.

El pensador mendocino relativiza el paradigma de la conciencia individual del filósofo, ya que, como se analizó anteriormente, el discurso filosófico se encuentra en un sistema de conexiones que componen el "universo del discurso". Este universo discursivo se da como espacio dinámico y conflictivo de objetivación del pensamiento, en el que se elaboran, expresan y resuelven, de alguna manera nunca definitiva, los problemas sociales. Al distanciar el discurso filosófico y al filósofo del solipsismo académico se sucede una modificación metodológica, ya que el sujeto histórico es parte del universo discursivo que toma en consideración los problemas sociales, pues la filosofía y las ideas están sumergidas en su historia. Al ampliarse el universo del discurso e incorporar la historia se toman en consideración formas de vida que no fueron tenidas en cuenta por las tradiciones académicas, cuestión que modifica la concepción misma de filosofía. El modo en que se correlacionan la noción histórica del sujeto y una ampliación de la filosofía queda expresado en estos términos roigianos:

Según sea la metodología, será la historia y aquella metodología a su vez dependerá tanto de lo que entendemos como sujeto histórico y en particular como sujeto del filosofar. Desde ya que si este sujeto es el que ha nutrido de libros de filosofía a nuestro continente, desde el siglo XIX, el panorama será uno; mas si entendemos que la filosofía no se reduce a un discurso tal como se lo ha practicado dentro de las tradiciones académicas, sino que hay formas vividas que pueden llegar a lo discursivo al margen de aquellas tradiciones, el panorama será otro. Y otra deberá ser la metodología y otra, en fin, será la filosofía. (Roig, 1988:12)

En este sentido queda destacada su noción de "filosofía para vida"; la filosofía deja de ser un saber abstracto o contemplativo para quedar abierto a la 
conflictividad propia de las relaciones humanas tal como sucede en la praxis cotidiana y que son parte del universo discursivo en el que se encuentra la filosofía. La historia, como elemento central de esta praxis, es el campo donde se disputan espacios de discurso, ya que éste implica espacios de poder. La conflictividad también se presenta de manera ínsita en la cultura. Como bien dice el autor:

Decir que la filosofía es una función de la vida es, pues, afirmar que es un hecho social y que muestra, los caracteres básicos de esa realidad, entre ellos, el más patente, el de la conflictividad o lucha, a través del cual se desarrollan las relaciones humanas. Y esa lucha, no ajena a una voluntad de poder, lo es contra la naturaleza, pero también de los hombres entre sí. Ella es la que impulsa a la historia." "...la filosofía como toda función de la vida no escapa a la ambigüedad. (Roig, 1993: 96-97)

La conflictividad es fundamental a la hora de pensar una epistemología antropofágica, ya que una de las nociones centrales de esta propuesta es el conflicto. La antropofagia asume la ineludible relación con la alteridad pero siempre de manera polémica. Se emprende una lucha con aquel a quien se considera ajeno, extraño, diverso, pero primeramente para ello hay que considerarlo otro. No es posible dejar de traer aquí la tan mentada lucha por la vida que da origen al concepto de reconocimiento desarrollado por Hegel en el capítulo cuarto de la Fenomenología del Espítu (1807), es decir, la "dialéctica del amo y del esclavo". La vida está atravesada por el conflicto, por la lucha y a partir de allí se crea la cultura, producto de este encuentro siempre ya conflictivo. Uno de los motivos por los cuales pretende traspasarse la noción de epistemología del sur y arribar a esta epistemología antropofágica es porque da cuenta de la conflictividad propia de la vida de manera patente, cuestión que no se encuentra explícitamente presente en la noción de sur. En este sentido el aporte del pensador mendocino de una filosofía para la vida siempre ya conflictiva resulta fundamental.

\section{Boaventura de Sousa Santos, acerca de las fronteras del conocimiento y las líneas abismales}

Para finalizar, se presenta la propuesta de Boaventura de Sousa Santos, ya que es un pensador que analiza críticamente las fronteras entre los diversos modos de conocimiento. Se considera oportuno analizar sus aportes ya que él habilita la posibilidad de traspasar las fronteras y trabajar con sujetos y fuentes que no han sido tradicionalmente considerados, que han quedado fuera 
del campo de lo aceptado científicamente y que es uno de los señalamientos que se busca con esta propuesta epistemológica. Boaventura de Sousa Santos plantea una lectura política y epistemológica del conocimiento en Occidente en función de las fronteras o líneas abismales. Estas líneas se dan a modo de límites que generan un hiato, una profunda distancia que separa el mundo en lo cognoscible y habilitado y lo que no puede ser conocido, pero que sin embargo comienza a filtrarse. Se dan a modo de grieta que deja de lado aquello que no puede ser aceptado ni siquiera como parte de una dicotomía (bueno-malo, correcto-incorrecto), pues está "más allá". Sostiene De Souza Santos que el pensamiento occidental moderno ${ }^{5}$ creó líneas que delimitan el mundo y lo separan en dos, en lo que respecta al conocimiento, pero también en las prácticas cotidianas de la vida, en la cultura e incluso en la concepción misma de humanidad.

Este lado de la línea, cuyos modos de conocimiento son la ciencia, la filosofía y la teología, produce la invisibilización del otro lado y de la línea misma a través de la cual este lado se define. Lo que queda visibilizado es la distinción que se produce de este lado de la línea, una dicotomía dentro del ámbito de lo posible que se sustenta en la línea abismal, que delimita al otro lado no reconocido. El conocimiento moderno y el derecho moderno son modos acabados del pensamiento abismal que establecen las distinciones de lo verdadero y lo falso, lo legal y lo ilegal, pero no tienen en cuenta que estas dicotomías se erigen en función de la línea abismal que deja del otro lado a lo que está por fuera de lo legal, como también a aquello que se considera incognoscible.

Estas tensiones entre ciencia, filosofía y teología han llegado a ser altamente visibles pero, como afirmo, todas ellas tienen lugar en este lado de la línea. $\mathrm{Su}$ visibilidad se erige sobre la invisibilidad de formas de conocimiento que no pueden ser adaptadas a ninguna de esas formas de conocimiento. Me refiero a conocimientos populares, laicos, plebeyos, campesinos o indígenas al otro lado de la línea. Desaparecen como conocimientos relevantes o conmensurables porque se encuentran más allá de la verdad y de la falsedad. ... Al otro lado de la línea no hay un conocimiento real; hay creencias, opiniones, magia,

\footnotetext{
${ }^{5} \mathrm{El}$ autor identifica al pensamiento occidental moderno como un pensamiento abismal de manera generalizada. Aunque tiene en cuenta que pueden existir otros casos de pensamiento abismal o que dentro del pensamiento occidental moderno se han dado, seguramente, formas alternativas o marginales, el mismo se presenta de manera hegemónica y es por ello que pone el foco en él.
} 
idolatría, comprensiones intuitivas o subjetivas, las cuales, en la mayoría de los casos, podrían convertirse en objetos o materias primas para las investigaciones científicas. (de Sousa Santos, 2010:13)

Este otro lado es el que pretende rescatarse en el presente trabajo: esos conocimientos que no han sido considerados "reales" ya que no se adaptaban al formato de la ciencia como paradigma del conocimiento moderno. En la ampliación de sujetos y de fuentes que propone tanto la filosofía intercultural como también la historia de las ideas y la filosofía latinoamericana es que se pretende abrir el espacio a aquellos que quedaron del otro lado de la línea abismal. Los sujetos colonizados, excluidos, empiezan a traspasar la línea y traen consigo sus creencias, sus comprensiones, su cultura que poco a poco gana lugar. Junto con Arturo Roig se prioriza la función de ruptura del concepto mismo, que se abre a nuevas mediaciones, a símbolos, a deseos, intuiciones y metáforas que implican a su vez otro modo de conocimiento, de relación intersubjetiva y de conformación de la subjetividad.

\section{Conclusión}

Las propuestas aquí presentadas pueden constituirse en la base de una epistemología pensada desde el sur, ya que las mismas buscan ampliar tanto las fuentes como los sujetos tradicionalmente considerados. Si bien desde perspectivas diversas, todas ellas pretenden romper las totalidades clausuradas, apartarse de la idea de sistema cerrado que no posibilita el surgimiento de lo otro, de la alteridad o de cualquier tipo de ruptura que genere algún desorden en lo establecido.

Las teorías desarrolladas avanzan en una concepción de la realidad que atiende a la diversidad, pero también a la conflictividad ínsita de la realidad, por lo que a partir de la modificación ontológica propuesta, puede pensarse una epistemología desde el sur cuyos fundamentos sean la contextualización y la ampliación del universo discursivo que dé cuenta de la filosofía como función para la vida. No se busca en este trabajo realizar una comparación, o analizar similitudes y diferencias de estos pensadores, sino que se considera que cada uno desde su mundo propio puede acercar diferentes formas de hacerse cargo de la complejidad en la que se esté inmerso. Desde esta propuesta se hacen confluir las voces que presentan cosmovisiones diversas y que convergen para pensar un problema que, en diversa medida, les resulta común: la posibilidad de construir una epistemología que contemple la pluralidad de mundos y a su vez la complejidad propia de los mismos. En función de lograr 
ese objetivo es que se vinculan estas propuestas y no con la intención de analizar falencias o límites de cada una de ellas, pues se considera que cada una en su medida aporta a la configuración de una epistemología que se piense desde el sur y ahora también antropofágica.

A partir de la propuesta inicial de una epistemología del sur, que cuestiona el conocimiento hegemónico, las dicotomías establecidas y las tramas de poder marcadas por la colonización y el capitalismo, se considera posible proponer una epistemología antropofágica, que se apropia de los aportes de diferentes pensadores y avanza hacia la creación de nuevas perspectivas de análisis que posibiliten la creación de conceptos acordes a estas latitudes y a estos procesos de producción de conocimiento. Ya no en términos de error, de adaptación, de mala copia, sino de una epistemología errática, disidente en algún punto, corriéndose de la dicotomía centro-periferia y revalorizando así un espacio propio de producción de conocimiento, que se da siempre de manera conflictiva. Los pensadores mencionados se vuelven fundamentales a la hora de avanzar desde un marco de epistemología del sur hacia una epistemología antropofágica, no solo por los aportes conceptuales en sí mismos, sino por el modo antropofágico en sí mismo que tienen de apropiación de otros autores y teorías. Fornet-Bentancourt lo hace en diversas instancias, con un cúmulo de autores diversos, con Hegel por ejemplo, yendo con y contra Hegel a la vez, pues lo desarma, lo digiere para apropiarse así de lo que considera valioso de ser incorporado. Otro tanto sucede con Sartre, autor al que le dedica su tesis doctoral; del mismo modo lo hace con Zubiri, mixturándolos por último con otros pensadores como Rodolfo Kusch.

Del mismo modo sucede con von Humboldt, ya que la rehabilitación que se hace de él proviene de pensadores dedicados a la literatura, que rompen las barreras disciplinares, toman a un geógrafo y generan una epistemología sustentada en lo que consideran es un pensamiento complejo. La apropiación de von Humboldt posibilita pensar alternativas a la colonización, aun en la época de su apogeo. Se hace posible pensar con él que la modernidad pudo ser otra, en función de otras tramas gnoseológicas, que privilegiaran el espacio y no así el tiempo -lineal-. También habilita en función de ello otros procesos poscoloniales, no necesariamente atado a la dicotomía de centro-periferia, colonizador-colonizado, etc. Más bien deglute estas dicotomías, para postular un pensar sincrónico, que dé cuenta de la diversidad y que confluya, de manera siempre provisoria, en una conciencia de mundo. Esta se da como síntesis, nunca homogénea, de una operación que podría considerarse de deglución antropofágica. 
Roig hace lo suyo con Hegel mismo y con la tradición de la filosofía, leyéndola a contrapelo, volviendo a insertarla en la historia y en la realidad social. Se apropia del concepto para tomar de él lo que considera necesita una filosofía matutina, una filosofía latinoamericana, que no se clausure en la ajena tradición occidental, sino que pueda romperse a sí misma y pensarse a sí misma a través de la herramienta misma del concepto. No hay un abandono de este por considerarlo eurocéntrico o hegemónico, sino una transformación y por qué no, como piensa Haroldo de Campos al referirse al Movimiento Antropofágico, una transvaloración, siempre conflictiva, pero que posibilita una filosofía para la vida.

Se pretende en este trabajo pensar junto con Boaventura de Sousa Santos y su propuesta de una epistemología del sur y de lo abismal como aquello que está más allá de las fronteras establecidas, más allá incluso de lo que está permitido ver, captar, pensar, aun en la disidencia; pero para incorporarle otros pensadores al banquete, deglutir el abismo, las dicotomías establecidas, e incluso las tramas de poder en las que se está inserto y generar perspectivas propias. Posibilitar el movimiento de aquellos conceptos tan estancamente establecidos, sin el miedo al error, a la mala copia, a la adaptación incorrecta, pues esta apropiación está guiada por la necesidad genuina de producir teoría, conceptos y perspectivas propias que den cuenta de un modo propio de conocer, percibir, y analizar la realidad por demás conflictiva en la que este Sur se encuentra inmerso.

\section{Referencias bibliográficas}

Adorno. T.W. (2005). Dialéctica Negativa. Madrid: Akal.

De Andrade, O. (2008). Escritos Antropófagos. Buenos Aires: Ediciones Corregidor.

De Campos, H. (2000). De la razón antropofágica y otros ensayos. México: Siglo XXI.

De Sousa Santos, B. (2006). Conocer desde el Sur: Para una cultura política emancipatoria. Santiago de Chile: Editorial Universidad Bolivariana.

De Sousa Santos, B. (2009). Epistemología del sur. México: Siglo XXI Editores.

Florez Malagón (2002). Desafios de la transdisciplinariedad. Bogotá: Universidad Javeriana. 
Follari, R. (1980). Interdisciplinariedad (los avatares de la ideología). México: UAM-Azc.

Fornet-Betancourt, R. (2001). Transformación intercultural de la filosofía. Ejercicios teóricos y prácticos de filosofía intercultural desde América Latina en el contexto de la globalización. Bilbao: Desclée de Brouwer.

Fornet-Betancourt, R. (2004). "El Programa de Diálogo Norte-Sur. Historia de un proceso y balance provisional" en: Filosofía para la Convivencia. Sevilla: MAD.

Kozlarek, O. (2009). "Conciencia de mundo" y humanismo. Herramientas conceptuales para la época de la globalización", en Rüsen. J., Kozlarek. O. Humanismo en la era de la globalización. Buenos Aires: Biblos.

Martí, J. ([1891]1975). "Nuestra América" en Obras Completas, t. 6. La Habana: Editorial de Ciencias Sociales.

Misch, J. (2004). "Consciencia universal”. Pensar, con Humboldt, el Proyecto de "otra" Modernidad, Reseña en Revista de Indias, LXIV, 231, 567574.

Roig. A. (1973). "Bases metodológicas para el tratamiento de las ideologías". En: Hacia una filosofía de la liberación latinoamericana. Buenos Aires: Editorial Bonun. pp 217-244.

Roig, A. (1988). "El método de pensar desde nuestra América". En: Serie cientifica $39, \mathrm{n}^{\circ} 12-14$, . Buenos Aires.

Roig, A. (1993). Rostro y filosofia de América Latina. Mendoza: EDIUNC.

Rolnik, S. “Antropofagia zombie”, en Brumaria 7 arte, máquinas, trabajo inmateria, disponible en: http://www.brumaria.net/textos/Brumaria7/ 14suelyrolnik.htm (Última consulta 20 de julio de 2013).

Scherbosky, Federica (2011). "La subjetividad antropofágica: aportes para una concepción devorativa de la vida”. En: Estudios de Filosofía Práctica e Historia de las Ideas. $\mathrm{N}^{\circ} 12$. INCIHUSA. CONICET. Mendoza. ISSN n 1515-7180. Pág 23-31.

Scherbosky, Federica (2013). "Antropofagia o acerca de desvíos y reapropiaciones". En: Muñoz, Marisa y Vela, Liliana. Afecciones, cuerpos y escrituras. Políticas y poéticas de la sujetividad. Colección Cuadernos de Cuyo. Qellqasqa. Mendoza. (163-174). ISBN 978-987-27766-8-8 